\title{
Private Tuition: High Stakes and Thorny Issues
}

\author{
Habib Yahiaoui ${ }^{1}$ \\ ${ }^{1}$ Faculty of Letters and languages, Mustapha Stambouli University, Mascara, Algeria \\ Correspondence: Habib Yahiaoui, Faculté des lettres et des langues, Université Mustapha Stambouli Mascara \\ 29000, Algeria.
}

Received: May 14, 2020

doi: $10.5539 /$ elt.v13n7p 88
Accepted: June 23, 2020

Online Published: June 25, 2020

URL: https://doi.org/10.5539/elt.v13n7p88

\begin{abstract}
Private tuition or shadow education is a self-contained activity. It is a system that exists parallel to the national education system. The scale of private tuition has witnessed a worldwide skyrocketing increase. The present research sheds light on the determinants that lead to the demand/ supply of private tuition. It examines the issue from the perspectives of the tutors, the tutees and the parents. The stratified sample in the study represents the population of JamaleddineElafghani Secondary School Mascara. The research tools utilised are a questionnaire to the learners, an interview to both the parents and the teachers and observation of sessions of PT to have a complete image of the situation under study. The results demonstrate that the national education system inadequacies like high stake examination, inexperience teachers and large classes have a great impact on the widespread of this phenomenon. The recommendation we suggest is regulating and thus harnessing this activity, or finding an alternative.
\end{abstract}

Keywords: academic performance, baccalaureate-exam, education system, Ministry of Education, private tuition

\section{Introduction}

\subsection{The Educational Context in Algeria}

As probably in any country in the world, education ranks high within the Algerian society. Parents, whether poor or rich-especially poor -place a great premium on education. They endeavour to provide their children with the best tools, the best means to succeed. They strive body and soul to make all the chances of success on their kids' side. They "hire" the most experienced teachers to coach their youngsters to help them understand all that is not grasped in the ordinary classes (Mogaka, 2009). To do this, parents have to cough up! This is all fine. What turns this usual practice to a bewildering situation is its continuous escalating tendency to englobe all levels, be it primary, middle or secondary. It will be of no surprise if this tendency reaches the university level. Therefore, it would be only legitimate to ponder over the factors behind the general craze for private tuition. Is this due to some weaknesses in our education system in general and the teaching approach in vogue in our country, namely the competency-based approach (CBA) in particular? Is the whole problem linked to the size of the classes? In other words, the larger the classes are the stronger tendency towards hiring a private is. Besides, it is well acknowledged that private tuition has an enormous impact on the academic achievement most especially in high stakes exams (like the baccalaureate exam) which play a crucial role in the learners' educational careers (Guill\&Lintorf, 2019). Yet, hardly do education policymakers tackle or even mention this issue. In a nutshell, most of the decision-makers like the different Ministers of Education of the different governments have been largely silent on the issue, in part because they do not dare tackle such a thorny issue that would raise the teachers' anger. This fact by itself justifies the need for this research.

\subsection{Private Tuition}

The term private tuition (henceforth PT) which has now become a global phenomenon (Bray, 2010) has been labelled differently by different researchers. For instance, Bray and Lykins (2012) call it shadow education as it mimics the mainstream. In fact, shadow education adapts and updates its syllabus every time the mainstream changes or expands (Bray \& Lykins, 2012, p.1). Yet, in all the definitions, we find the same features as the setting, the form and the aim. PT consists of the provision of well-structured supplementary instruction that takes place outside and parallel to the formal schooling system for a fee. There are instances where PT takes place at school. There are schools in the country, which allow teachers to provide PT inside the institutions on Tuesday afternoon and Saturday morning. These institutions major concern is to give the learners a decent, comfortable 
and secure place to study. These are sporadic, rare instances where 'courageous' headmasters take purely personal illegal initiatives to help their pupils. This is but a vain attempt to harness the chaotic situation engendered by the total absence of control over the shadow education.

Before proceeding any further, it will be beneficial to give an overview of the considerable global expansion of this phenomenon. To start with, it is a fact that PT is not peculiar to any country, least of all our country. It is a universal practice. PT is present in countries as economically and geographically diverse as Cambodia, Singapore and Japan in Asia; Egypt, Kenya and Morocco in Africa; Romania, Germany and United Kingdom in Europe, USA, Brazil in America (Bray, 2007). However, the scale of PT varies from one country to the other. Studies (Bray, 2007, 2010; Bray \& Kwok, 2014; Baker \&LeTendre, 2005) have brought to the open that the Japanese and the Brazilian rate are the highest with respectively $70 \%$ and $50 \%$ of the learners receiving PT while the German rate is the lowest with only $14 \%$. The magnitude of PT according to Bray (2007, p.23) is tightly linked to the cultural, educational and economic factors of the country; but that is not the issue of the present paper.

PT is dispensed in three major forms: individual tutoring, small group tutoring and large class tutoring. The first form is required by wealthy clients who desire individualized teaching for their children. Usually, the setting is the clients' house. The small group tutoring as mentioned by Mogaka (2009, p.31) happens at the premises of the mainstream schools. They are accomplished by the mainstream teachers outside the formal class hours who get pay in return. The last type is provided by private tutor centres. Here, we find entire classes rigorously arranged not only according to their levels but also to their needs. In recent years, and with the development of technology tutoring is provided via the Internet.

The incessant rising tendency of PT is due to four predominant factors: economic, social, cultural and educational. In the job market, competition is so harsh that one must be armed with quality academic credentials in the given field of specialization (Mogaka, 2009, p.34). Children of wealthy families are shown to benefit more from private tutors. To their parents, these studies are a form of investment that would guarantee 'better careers and more rewarding jobs' (Mogaka, 2009, p.34). Bluntly stated, the quality of the university one enrols in, determines his career. The more renowned the university is the more distinguished occupation one will get. Some rich students who pass the baccalaureate exam with unsatisfactory scores usually sit for the exam a second time. They aim at reaching the required grade for universities offering more advantageous future careers as the faculty of medicine for example.

Mainstream teachers who receive poor official wages tend to encourage PT to gain extra income. This is also true for university students who subsist by providing PT to their peers or pupils who have difficulties in their studies as a part-time job. In a word, PT is a lucrative uncontrolled tax-free activity where the state receives not a penny because it is irregular and seasonal (Silova 2010, cited in Bray \& Lykins, 2012, p. 63).

Some families see PT as a parental duty (Ireson \&Rushforth, 2014). To supervise their children education, they hire private tutors at home. These families grant a huge value on education in general and place a great premium on their children learning. One social reason that could explain the craze for PT is the peer pressure among both students and parents. Some parents send their children to PT centres because they do the same thing as the other parents in the neighbourhood. When parents find out that other parents are sending their children to PT centres, they get worried and do the same (Sharwva, 1997, cited in William, 2017). Bray (2007) has highlighted the idea of remorse. Indeed, some feel responsible for their children failure if they do not pay for PT. It remains illegal.

Researchers like Stevenson and Stigler (1992) or Kim (2006) have argued that culture has a considerable impact on the scale of PT. There exist some cultures where an enormous social and cultural significance is attached to "academic credentials and meritocracy and the resultant obsession with education" (Kim, 2006, p.156). Many Asian countries place emphasis on effort. The learners have to attend PT sessions to ameliorate their academic performance. The more he does, the better he will become. However, in European countries and North American cultures, stress is put on ability. Stevenson and Stigler (1992) have explained why the craze for PT is less apparent in these countries than the ones in Asian cultures.

The importance of the educational factor lies in the fact that rich and poor families alike place a great premium on education. Indeed, the educational factors drive the need for PT more than the social and the economic factors combined (Mogaka, 2009). To ensure and augment their prospects of a good academic performance in the national examination, students strive to enrol in PT. This will ensure better labour market opportunities in general and a desired career in particular. 


\subsection{The Impact of Private Tuition}

There exists not the slightest doubt about the impact of PT on individuals' academic achievement; though, many researchers like (Bray, 2005) have confessed that it is hard to identify exactly that impact. The reasons are numerous. To cite but a few, there is a myriad of factors involved in the process of academic achievement of any learner. Bray (2005, p.46) has declared that because of the uniformity in many characteristics and attributes, it is problematic to compare students who take PT to those who do not. In other words, the impact of PT overlaps with other factors.

Researches on this topic do not concur. Some of these studies such as the ones conducted in Mauritius, Greece, Germany and Kenya (Bray, 2005) have documented a positive impact of PT on the learners' accomplishment. Others have demonstrated that there may be no correlation between PT learners' achievement (Bray, 2005), and henceforth has no noteworthy significance on the learners' overall achievement.

Dang and Rogers (2008) have stated that PT is designed as remedial sessions to enable some students to keep pace with their classmates. In these sessions, the focus is on what is missed in ordinary classes. Other forms of PT are formulated as additional assistance to push the boundaries further and further to provide the PT takers with more advantages over their peers. This enhancement is noticed when PT helps students understand what is taught in mainstream classes. This is the case in our country because all that is done in PT sessions is but a re-teaching of what is taught in ordinary classes. Yet, sometimes this kind of tutoring is reported to harm mainstream classes. The leaners are no more motivated in what is happening in the usual classes because they know that everything will be clearer in their PT sessions. In this respect, Hussein (1987, p.92) has stated: "as long as students can pay someone who will show them how to pass their examinations, they do not need to attend school classes except when they are required to do so by school regulations".

The impact of PT has considerable significance in some cases because it has examination-oriented objectives. It stresses what is perceived as relevant for passing an examination. In other cases, it focuses on passing the examination with the required grades that enable the learners to choose the branch they want. In our case, many learners prefer sitting for the baccalaureate exam a second time rather than enrolling in studies that they or their parents do not favour.

A not far-fetched impact of PT can easily be cited here. PT can not only maintain the social inequalities but also increase the frustration of those who cannot afford it. As a consequence, those who succeed are those who can pay.

Besides being well-off, PT is tightly linked to the degree of education of both parents. In a research, Kwan-Terry (1991, p.88) finds that the less educated the parents are and the more willing to enrol their children in tutoring they seem. This is utterly true in our society where the illiterate parents strive to provide their children with the best education they could afford.

In the long run, PT may impact society negatively in general since it may help maintain matters as they are within a society. The status quo is preserved as the social inequalities increase because PT is more obtainable by the rich than by the poor.

PT is an extremely controversial issue with contradicted viewpoints. It sparkles hotly debates in our country. On the one hand, PT is a lucrative business that is deeply rooted in the practices in the education system. On the other hand, it is a business that is not controlled or even harnessed to make it legal. As such, it is but ignored or tolerated chiefly because it is provided in a marketplace beyond the remit of the Ministries of Education (Bray \& Lykins, 2012).

As long as the traditional type of examinations continues to be practised at schools and universities, PT will prevail stifling all kinds of creativity, widening the gap between social classes and maintaining the status quo within a society. With the introduction of portfolio assessment, it is doubtful whether PT continues to exist any longer. But whether this alternative assessment is fully comprehended and put into practice in our schools is a different kettle of fish (Yahiaoui, 2017, p.39).

\subsection{Research Purpose}

PT is preponderating in Algerian society because learners have never been trained to be autonomous. They have been assisted from a very young age. This kind of spoon-feeding education is commonplace, where there is a great dependence on teachers outside normal schooling. Consequently, whenever learners encounter difficulties, illiterate parents tend to think that tutoring is unavoidable for they cannot themselves help their children with the tasks (Bray \& Lykins, 2012, p.55). Parents pay the sum of money charged for better quality and even greater quantity. 
This study aims at investigating the factors that drive students to attend PT sessions and by the same token, how teachers cope with in the Algerian context. The study will also highlight the impact- be it positive or negative- of PT on the national education in general and on the learners' careers in particular. It is also pertinent to find out the learners' stances and attitudes towards the effects of PT. The National Ministry of Education strove vigorously -though vainly- to stop this shadow education. Is there a way of putting an end to this phenomenon that keeps expanding year after year?

\subsection{Hypotheses}

These are broad objectives, but the sole concern of the present research is to find out the reasons behind the prevalence of private tuition and at the same time to inquire about the influence of PT on the baccalaureate students' academic achievement. Furthermore, we intend to tap into the idea of whether PT influences the course of the national education system. Hence, this study attempts at answering the following research question:

RQ: What are the reasons behind the craze for PT?

H1: The general spread of PT is due to the weaknesses of our education system.

$\mathrm{H} 2$ : There is a correlation between large classes and the general spread of PT.

\section{Method}

\subsection{Research Design}

Cohen, Manion and Morrison (2018, p. 32) indicate that mixed method research premise is that the use of quantitative and qualitative approaches in combination provides a more comprehensive and complete understanding of the research problem under study than a single approach would yield. This combination enables the researcher to increase the accuracy of data and reliability through triangulation. Thus, this study adopted used both quantitative and qualitative methods to interpret and analyse the results of the study.

The present research utilises three tools, namely an interview with fifteen (15) teachers who offer this kind of service every year, to gather the needed data. To have a complete view of the problem, another interview was given to twenty-three (23) parents to have a plain idea of their perceptions on the practice of private tuition. How this practice is currently done is also relevant to the present paper. Therefore, we find it pertinent to observe the process of providing such lessons with such teachers. These teachers are not chosen randomly, but rather because they supply private tuition to baccalaureate students every year. How do PT takers this activity? Though we believe that whole future research would be devoted to the study of this particular point, we have introduced a questionnaire to have a complete image on the learners' enrolment reasons in such tutorials.

\subsection{Participants' Characteristics}

To confirm or refute these hypotheses, we have chosen the population of third-year students at JamaleddineElafghani Secondary School. This school is the most ancient school at Mascara and was erected in 1927 during the French colonial period.

Table 1. The Population and the Sample of the study

\begin{tabular}{cccccccc}
\hline Stream & SC & MA & EC & T/MA & FL & L\&P & TOTAL \\
\hline Population & 136 & 31 & 16 & 27 & 33 & 57 & 300 \\
Sample & 31 & 11 & 10 & 13 & 15 & 20 & 100 \\
\hline
\end{tabular}

$(\mathrm{SC}=$ science, $\mathrm{EC}=$ economics, $\mathrm{MA}=$ Maths, $\mathrm{T} / \mathrm{MA}=$ technical maths, $\mathrm{L} \& \mathrm{P}=$ literature and philosophy, $\mathrm{FL}=$ foreign languages)

To secure the representativeness of the study, we have opted for the stratified sampling method. A stratum is taken from each mainstream. The sample comprised 100 male and female students aged between 17 and 21 .

\subsection{Data Collection}

In the current study, we have adopted the triangulation of data to ensure a larger quantity of valid and reliable information. We made use of three tools: the questionnaire, the interview and the observation of some tutoring sessions to enhance the robustness and credibility of our conclusions and recommendations.

Based on the research question, a questionnaire was developed and distributed to all the participants in English. We asked the students to fill in the form related to reasons for taking PT, how PT help in understanding and improving their grades and the general organisation of the PT session. We asked the respondents about the remedial sessions at school, and about the studies, they yearn to attend the university. 
The face to face interview with the teachers of JamaleddineElafghani Secondary School was meant to test the hypothesis of whether PT existence is related to the weaknesses of our national education system. Therefore, the questions tackled items related to the conditions of their daily practice, stretching from the size of the classes to the classroom management, including assessment and all that it entails. As an important stakeholder, the parents' viewpoint on this issue was also sought through a semi-structured interview.

While the two interviews were semi-structured to recover the data missed by item non- response, we targeted the observation towards queries about the size of PT classes, its management, and its settings. We concentrated on the teacher's interaction with his tutees, and on how these tutees interact with each other. Our observation aim was to scour the teaching practice, which encompasses the activities, the overall behaviour of both the tutor and the tutees, not to mention the skills being developed.

The data obtained from the students' questionnaire were proceeded with Statistical Package for the Social Sciences (SPSS) version 26.0. The semi-structured parents and teachers' interviews were tape-recorded and transcribed. Then, the data were content analysed in two main sections according to the two hypotheses.

\section{Results}

The three deployed research tools generated a rich database covering many aspects of the practices of PT, and they included spontaneous answers and comments by the participants. The questionnaire contained 11 questions relating to the participants', age, stream, and reasons for enrolling in PT.

The results provide a clear picture as to who takes PT and under which conditions. As far as gender perspective in PT is concerned, the results show a higher percentage of girls attending PT than boys, as only $47 \%$ of boys attend PT in comparison 53\% of girls.

Table 2. Students Receiving PT in Different Streams (\%)

\begin{tabular}{ccccccc}
\hline Stream & SC & EC & MA & T/MA & L\&P & FL \\
\hline$\%$ & 80.65 & 80.65 & 72.72 & 69.23 & 60 & 46.66
\end{tabular}

$(\mathrm{SC}=$ science, $\mathrm{EC}=$ economics, $\mathrm{MA}=$ Maths, $\mathrm{T} / \mathrm{MA}=$ technical maths, $\mathrm{L} \& \mathrm{P}=$ literature and philosophy, $\mathrm{FL}=$ foreignlanguages)

The extent of PT is significantly high in the science stream and economics with $80.65 \%$. The average percentage of students enrolling in PT is $72.72 \%$ for mathematics stream against $69.23 \%$ for technical mathematics. In the fifth position comes the literature and philosophy stream with $60 \%$ just before foreign languages stream with $46.66 \%$.

Table 3. Different Forms of PT

\begin{tabular}{cc}
\hline Private tuition centres & $57 \%$ \\
\hline Small group & $39 \%$ \\
Home tuition & $4 \%$
\end{tabular}

The Table 3 shows that more than half of the tutees (54\%) enrol in centres, while $39 \%$ in small groups. Those who enrol in one-on-one basis at their own homes constitute a negligible proportion (4\%). As for the length of time devoted to PT, the research revealed that the majority of the respondent, that is, $65.22 \%$ spend 2 to 4 hours in PT. 32\% of them spend less than $2 \mathrm{~h}$ and just $3 \%$ spend more than $4 \mathrm{~h}$.

Table 4. The Tutees 'Questionnaire Results

\begin{tabular}{ccccccc}
\hline Reasons & 1 & 2 & 3 & 4 & 5 & 6 \\
\hline$\%$ & 100 & 87 & 82 & 73 & 54 & 39 \\
\hline
\end{tabular}

(1= Pass the Baccalaureate exam, $2=$ Teachers do not teach well at school, $3=$ Get higher academic grades, $4=$ Large classes, 5= Inexperienced teachers, $6=$ Get higher marks in the Baccalaureate exam)

All the respondents assert that they enrol in PT mainly to succeed in the secondary school high-stakes examination: the baccalaureate. A large percentage of the respondents (87\%) who attend PT points out that teachers do not teach well at school because of a myriad of constraints like finishing the syllabus in time. The vast majority, that is, $82 \%$ strongly believes that PT sessions enable them to get higher academic grades, and guarantee them academic development in the long run. The overall results show that the size of the classes is considered as the major reason for PT enrolment and comes as an obstacle to sustainable educational development. Admittedly, a vast majority ( $73 \%)$ of the students mention the fact that they could not understand 
teaching in such large classes. More than half of the informants (54\%) considers inexperienced teachers or even the absence of teachers in subjects like mathematics, physics, science, philosophy as a major reason for PT. These newly recruited teachers are constrained to teach classes with a decisive final exam. The last but certainly not the least explanation for this craze is to increase one's average in the baccalaureate (39\%) to maximize ones' chances to ensure the solicited university branch.

Table 5. The Parents' Interview

\begin{tabular}{ccccccc}
\hline Reasons & 1 & 2 & 3 & 4 & 5 & 6 \\
\hline$\%$ & 100 & 90 & 80 & 75 & 72 & 48 \\
\hline
\end{tabular}

$(1=$ Guarantee their children success at the baccalaureate exam, $2=$ Strikes, $3=$ More individual attention, $4=$ Inexperienced teachers, $5=$ Large classes, $6=$ Undisciplined classes and school)

All the parents we interviewed responded that the reason that pushes them to spend money on PT is to guarantee their children success at the baccalaureate exam. They confessed that they feel obliged to do so because of the lack of experienced teachers, the lack of discipline in overcrowded classrooms. PT, according to the majority of them $(80 \%)$, offers more individual attention and prepares the students to pass the examination. They claimed that, had there been the right conditions, they would not have turned to PT to ensure the success of their children. They believe that with large classes, continuous strikes declared now and then, not to mention fresh, inexperienced teachers, one cannot ensure ones' children success in the baccalaureate exam, let alone guarantee their enrolment in the desired university branch. The interview also reveals that teachers are more concerned with covering the full syllabus before the ends of the school year. Being in such a hurry, they pay less attention to assessing their students' understanding. The culmination of all these factors, according to the majority of the interviewees $(90 \%)$, puts considerable pressure on students and parents as well.

The majority of the teachers are well-known, well-experienced practitioners who have been providing PT for more than 15 years. They provide this kind of education either in their own homes or in private tuition centres because of the increasing demand. All the teachers confessed that they do it for extra income. According to the majority of the teachers, students who pay for PT are good, highly motivated learners who want to improve their academic achievements. The majority of them reveal that in PT sessions, they can spend more time on how to solve problems. One tutor said his lessons focus primarily on test preparation. He added that it is almost impossible to do the same in normal classes because he is always struggling to finish the syllabus. All the tutors explained that large size classes are a prime impediment for efficient teaching and learning. The majority of them asserted that large size classes are the PT demand main driver.

\section{Discussion}

The research question in this study concerned the reasons behind the craze for PT in Algeria. Prior to this study, it was assumed that the general enthusiasm for PT is due to the weaknesses of the Algerian education system. Based on the quantitative data gathered from the students' questionnaire and the qualitative data collected from the parents' and the teachers' interviews, the reasons could be easily sorted under one heading, namely the weaknesses of the national education system. This heading encompasses:

1. high-stake examination

2. teachers do not teach well at school

3. large classes

4. inexperienced teachers

5. strikes (loss of school working days)

6. getting high grades.

These problems put huge pressure on both the learners and their parents, let alone the teachers who have to assure the success of his tutees. The study confirms the first hypothesis that assumes that the general craze for PT is due to the weaknesses of the national education system. The assumption that there is a correlation between large classes and the general spread of PT turned out to be accurate. Data collected from both the questionnaire and the interviews confirm that large size classes are one of the main reasons for receiving PT. In large classes, teachers state that they cannot give more practice, individualized attention and at the same time complete the syllabus.

The findings are interrelated, and they lead to the same conclusion: PT will continue its widespread. As long as families feel that schooling is inadequate to meet their children's needs, and as long as teachers feel that their 
incomes are too low, the craze for PT will not be restrained. PT is the outcome of the actual educational situation with all its challenges. To start with, during the last decade, many experienced teachers have retired in mass leaving schools to novice inexperienced practitioners. This has made matters worse to an already awkward situation, where there is a continuous demand for PT to pass a high stakes examination, on the one hand. On the other hand, well- experienced teachers try to satisfy the widespread demand to improve their monthly earnings. Finally, parents are caught between the hammer and the anvil and have to pay to secure a better career to their children.

There is no particular distinction between the teaching process in mainstream classes and PT sessions worth mentioning. PT only mimics the mainstream (Bray, 2010). The only difference lies in the learners' motivation that has a great impact on the teacher's behaviour. All the tutees have a goal, and they pay good money to attain that goal. Both the tutor and the tutees acknowledge this. As a result, hardly do we encounter a problem of discipline in these sessions. Furthermore, the tutor knows that the success of the tutees is his sole evaluation.

The second difference lies in the way the tutor teaches. First, the tutoring takes place in such a stress-free, enjoyable atmosphere where the learners have no fear of asking questions. Instead of restricting the tutoring sessions to teaching, the tutor provides his learners with strategies and skills to understand and answer examination questions: the know-how. It is practically impossible to provide this in mainstream classes because of constraints like time and size of the class. This utterly highlights the weaknesses of our national education system and confirms both hypotheses.

The issue cannot be solely explained by the size of the classes. Bray and Lykins (2012, p.27) concede that in some parts of the world, parents favour small classes where the learner has more opportunity to benefit from interactive pedagogy and individualised instruction. He can get clarifications and illustrations to his spontaneous questions. However, we may find mainstream classes of 15 students of whom 10 pay for PT. We may also find PT classes of 35 learners in the county. Bray and Lykins (2012, p.27) mention classes exceeding 100 tutees in Sri Lanka. Class size has been the subject of some controversy (Wossmann\& West, BLachford et al. 2011 cited in Bray \& Lykins, 2012). The size of the class may affect the learning process, but when there is rigour, discipline and motivation, there will be no need for PT. However, whether these three elements can be gathered, we wonder. Remedial sessions do exist at schools. They are compulsory here, and optional elsewhere. Neither the learners nor the teachers are willing to attend these remedial sessions, which are mostly limited to less able learners. We conclude that this is due to poor handling of an important issue: remedial work. This fact goes in line with the first hypothesis.

We may speculate about the spread of this phenomenon. We may state that tutors are providing their teaching in inappropriate places such as tiny rooms, huge cold garages, shops or decent centres. We may add that it is a lucrative business. Yet, we can never deny its effectiveness (Bray, 2010). Henceforth, in such issues, the either-or solution, namely eradicating PT or shutting an eye on it and leaving it at its present state of things, is not the wisest resolution. Indeed, the Minister of Education-Mrs Benghabrit- has taken drastic measures to stamp PT out.

The different governments that the country had had during the last two decades or so have always managed to assuage the teachers' discontent by infusing them with hopes for future gain. This tactic has succeeded countless times, but its chances of success have diminished with the skyrocketing spread of social network services such as Facebook. Social media are finally causing teachers to disregard the honeyed words of education ministers. Now caught between the hammer and the anvil, these latter strive to satisfy the teachers' demands while considering the parents' as well. This tug of war has resulted in repeatedly strikes that paralysed the national education system for months. Parents are aware that their children are used as hostages and are puzzling over how to catch up with the schedule by the end of the school year. To put it in a nutshell, when delineating PT, we discover all that is not working properly within the education system.

Instead of stopping a system that has been in parallel practice to the formal system of education; a system that has proved its effectiveness in providing academic support and overcoming school deficiencies for decades (Bray, 2009), why not harness it. By harnessing it, we mean to make it legal. In other terms, there is an urgent need to regulate PT for the mere reason that it is by no means a self-contained activity. Its sole existence is to enhance the students' learning of school subjects.

Rules will give PT a legal status to secure its continuity. Therefore, more investments will enhance this lucrative business. Governments will collect taxes. Regulations will impose the minimum qualifications for the tutor, and restrict the class size. The clients -the parents- will have a broader image of who does what, where, when, how, and how much. In the long run, teachers in developing countries will be providing their tutoring in decent, secure 
places with all the minimum required facilities. Rules will only make things better, and PT will explore other horizons such as e-tutoring.

\section{Conclusion}

The present study aimed to investigate the reasons behind the craze for private tuition in an Algerian context. The results previously presented clearly confirmed the two assumptions. Accordingly, there is a significant relationship between the weaknesses of the national education system and the widespread of PT. The study found high stakes examination, lack of experienced teacher in mathematics, physics and science, large size classes the most repeated weaknesses. These reasons are interrelated and affect each other. For instance, an inexperienced teacher working with a large class will see his learners seeking tutoring to improve their grades and passing the baccalaureate exam. Furthermore, the second hypothesis that assumes there is a correlation between large size classes and PT is confirmed.

In no other affair is prevention so much better than cure, as in education. The effectiveness of PT on the learning process in the short term, and on one's career, in the long run, is indisputable. We conjecture that a myriad of variables correlates in this issue. We must scrutinize and weigh up all these variables. Leaving the actual situation as it is will lead to the spread of private schools, which in their turn will unquestionably lead to widening the gap between rich and poor.

There are more pressing reasons to harness PT or find an alternative. An interviewee states that PT is no longer beneficial for less -able learners unless they are tutored alone. Those who attend such courses are good learners who aim at improving the exam results: scoring the possible highest average. Furthermore, "star" tutors scorn this kind of tutees because they fear for their reputations if they fail in the baccalaureate. So, what to do with these learners? Shall we leave the less-able behind? It follows that the only course of action open to the government is to put rules to this uncontrolled practice. We could duplicate the Korean example to address the issues of tutoring. The Republic of Korea has launched two initiatives: The Educational Broadcasting System (EBS) and the Cyber Home Learning System (CHLS) to provide an alternative to private tutoring (Bray \& Lykins, 2012, p.57).

\section{References}

Baker, D., P., \& LeTendre, G., K. (2005). National differences, global similarities: World culture and the future of Schooling. Stanford: Stanford University Press.

Biswal, Bagala P. (1999). Private Tutoring and public corruption: A Cost-Effective Education for Developing Countries. Developing Economics, 37(2), 222-240. https://doi.org/10.1111/j.1746-1049.1999.tb00232.x

Bray, M., \& Kwo, O. (2014). Regulating Private Tutoring for Public Good Policy: Options for Supplementary Education in Asia. Hong Kong: UNESCO Asia and Pacific Regional Bureau of Education.

Bray, M., \& Lykins, C. (2012). Shadow Education Private Supplementary Tutoring and Its Implications for Policy Makers in Asia. Philippines: Asian Development Bank.

Bray, M. (2005). Private Supplementary Tutoring: Comparative Perspectives on Patterns and Implications. Hong Kong: Oxford International Conference on Education and Development.

Bray, M. (2007). The Shadow Education System: Private Tutoring and Its Implication for Planners. Paris UNESCO: International Institute for Educational Planning.

Bray, M. (2010). Blurring Boundaries: The Growing Visibility, Evolving Forms and Complex Implications of Private Supplementary Tutoring. Hong Kong: comparative education

Dang, H., A., \& Rogers, F., H. (2008). The growing phenomenon of private tutoring: does it deepen human Capital; widen inequalities, or waste resources? The World Bank research observer, 23(2), 161-200. https://doi.org/10.1093/wbro/lkn004

Guill, K., \& Lintorf, K. (2019). Private tutoring when stakes are high: Insights from the transition from primary to secondary school in Germany. International Journal of Educational Development, 65, 172-182. https://doi.org/10.1016/j.ijedudev.2018.08.001

Hussein, M. (1987). Private tutoring: a hidden educational problem: in educational studies in mathematics. Springer, 18(1), 96-124. https://doi.org/10.1007/BF00367916

Khamis, M., A. (2012). Assessing Stakeholders Perceptions on Private Tuition in Zanzibar. USA: University of Massachusetts.

Kim, H. (2006). Korea's obsession with private tutoring. Institute of educational planning and administration, 
11(1), 11-17.

Kwan-Terry, A. (1991). The Economics of Language in Singapore: Student in Use of Extracurricular Language Lessons. Journal of Asian Pacific Communication, 2(1), 69-89.

Mogaka, A., G. (2009). Factors that influence the need for private supplementary tuition in secondary schools: a case study of selected schools in Borabu district of Nyamira county, Kenya. Kenya: university of Nairobi.

Stevenson, H., W., \& Stigler, W., S. (1992). The Learning Gap: Why Our Schools Are Failing and What Can We Learn from Japanese and Chinese Education. New York: Summit Books. https://doi.org/10.1002/leap/50065

William, S. (2017). Students' perspectives on buying private tuition services. International journal of research studies in education, 7(2), 105-119. https://doi.org/10.5861/ijrse.2017.1789

Yahiaoui, H. (2017). Portfolio Assessment to enhance students' writing skill. Kiraat, 1(7), 31-42.

\section{Copyrights}

Copyright for this article is retained by the author(s), with first publication rights granted to the journal.

This is an open-access article distributed under the terms and conditions of the Creative Commons Attribution license (http://creativecommons.org/licenses/by/4.0/). 